\title{
Spectrum Management in the 6G Era: The Role of Regulation and Spectrum Sharing
}

\author{
Marja Matinmikko-Blue \\ University of Oulu \\ Center for Wireless Communications \\ Oulu, Finland \\ marja.matinmikko@oulu.fi
}

\author{
Seppo Yrjölä \\ Nokia; University of Oulu \\ Center for Wireless Communications \\ Oulu, Finland \\ seppo.yrjola@nokia.com
}

\author{
Petri Ahokangas \\ University of Oulu \\ Oulu Business School \\ Oulu, Finland \\ petri.ahokangas@oulu.fi
}

\begin{abstract}
Spectrum management plays a key role in the deployment of new wireless technologies. Regulators in the 5G era have introduced a variety of spectrum management approaches that allow the deployment of new cellular networks including traditional exclusively nationwide licensing, local licensing and unlicensed approaches involving varying levels of spectrum sharing. The upcoming $6 \mathrm{G}$ era in the $2030 \mathrm{~s}$ will face new challenges resulting from the ever-increasing variety of considered spectrum bands for 6G with drastically different propagation characteristics and the increasing fragmentation of spectrum management approaches. This paper provides an overview of spectrum management for mobile communication networks including the most recent $5 \mathrm{G}$ spectrum decisions. The paper discusses the role of spectrum sharing in the upcoming 6G era and related enabling technologies. The paper opens the door for 6G spectrum discussions with an emphasis on what is different in $6 \mathrm{G}$ while taking into account the challenges arising from the underlying regulatory environment.
\end{abstract}

Keywords-5G, 6G, spectrum management, regulation

\section{INTRODUCTION}

Spectrum management decisions made by the regulators aim at efficient use of the scarce natural resource while ensuring fairness between the different stakeholders that want to use the radio spectrum. Spectrum management involves decision making in the presence of conflicting stakeholder views as most of the spectrum bands considered suitable for mobile communications have already been allocated to various other wireless services [1]. The regulators play a key role in defining the rules and conditions for spectrum use that all need to follow which is getting increasingly difficult due to increasing demands.

Mobile communication sector has been successful in gaining access to new spectrum bands over the past several decades leading to mass deployments of $2 \mathrm{G}, 3 \mathrm{G}$ and $4 \mathrm{G}$ networks globally. This process at its highest international level at the World Radiocommunication Conferences (WRCs) arranged by the International Telecommunication Union Radiocommunication sector (ITU-R) has made significant spectrum allocations to the mobile service and identified them to be used for International Mobile Telecommunication (IMT) systems in multiple occasions in (e.g., 2007, 2012, 2015, and most recently in 2019) [2]. This has led to wide-spread deployment of mobile communication networks but also rivalry between different spectrum users, for which one major solution is the development of advanced spectrum sharing management techniques and models.

At the national level, administrations have controlled the mobile communication market through their spectrum awards decisions and other related regulations that typically have given the rights to deploy and operate cellular mobile communication networks and be telecommunications service providers to a handful of mobile network operators (MNOs). Most recently, 5G spectrum awards decisions have taken place in a number of countries and the first deployment of $5 \mathrm{G}$ networks have been announced. For the first time, 5G brings along a plethora of spectrum management approaches that were not considered in prior generations [3]. Traditional nationwide long-term spectrum licenses are complemented with local 5G licenses [4] and unlicensed access [5], which represents a major paradigm change in spectrum management for mobile communication networks.

At the same time as $5 \mathrm{G}$ deployments have been announced, research on $6 \mathrm{G}$ networks has already started with the launch of world's first 6G White Paper in 2019 [6]. The 6G research vision presented in [6] targets the year 2030 when our society will be data-driven, enabled by near-instant wireless connectivity. Spectrum will continue to play an important role in $6 \mathrm{G}$ as any prior generation of mobile communication networks and will face increasingly complex setup in terms of the variety of potential spectrum bands and spectrum management approaches, not to mention the existing incumbent usage in the bands.

This paper discusses spectrum management in the context of mobile communication networks moving beyond $5 \mathrm{G}$ networks towards $6 \mathrm{G}$. The $6 \mathrm{G}$ spectrum discussions are still at infancy due to the major efforts of $5 \mathrm{G}$ spectrum that took place in preparation for WRC-19. The spectrum management approaches used for mobile communication networks are presented and the role of spectrum sharing in current and upcoming mobile communication systems is reviewed. Challenges of spectrum management in the $6 \mathrm{G}$ era are outlined together with an outlook on the future. The rest of this paper is organized as follows. Section II presents an overview of spectrum management approaches. Section III presents the key enabling techniques for spectrum sharing. Section IV opens the spectrum discussion for 6G. Challenges and future outlook is given in Section V, followed by Conclusions in Section VI.

\section{OVERVIEW OF SPECTRUM MANAGEMENT IN MOBILE COMMUNICATIONS}

Spectrum management aims at efficient utilization of the scarce national resource and has taken different forms over the years. In general, spectrum management approaches can be divided into three categories [3] including administrative allocation [7], market-based mechanisms [8]-[9], and unlicensed commons approach [10]. In the following, spectrum management in the context of cellular mobile communication networks is reviewed with an emphasis on recent $5 \mathrm{G}$ spectrum decisions. 


\section{A. Spectrum Management Approaches}

The major spectrum management approach for the first generations of mobile communication networks has been administrative allocation where the national regulators have defined individual spectrum access rights to deploy cellular networks and decided who gets the rights. Regulators have also defined the related rules and conditions, such as possible coverage obligations. In administrative allocation, the market is in the hands of the regulators who solely define the number of MNOs in the market and decide on the admittance of any new market entry. Regulators have gradually opened the mobile communication market to new entry to compete with state-owned monopolies resulting in a number of benefits over the past decades [1]. The administrative allocation continued to be in use for $3 \mathrm{G}$ and $4 \mathrm{G}$ spectrum license awards in some countries but faced increasing criticisms on the fairness of regulators' decision making [11].

Another major spectrum management approach, the market-based mechanism [8], emerged early on to allow the spectrum awards decisions to consider the market in contrast to pure regulator dominance. Market-based mechanisms in terms of defining individual spectrum access rights and allowing the markets to define who values the spectrum the most and should be granted the rights to use the spectrum. The most famous market-based mechanism is the use of spectrum auctions [12], which has became a key tool in the $3 \mathrm{G}$ and $4 \mathrm{G}$ era for regulators in several countries to define who gets the limited number of individual spectrum access rights while the number of MNOs wishing to enter the market kept increasing. Market-based mechanisms typically introduced the opportunity for the license holders to lease or trade their spectrum or parts of their spectrum, which has introduced flexibility into the market but not taken place very frequently [13]

The third major spectrum management approach, the unlicensed commons approach [10], [14], on the other hand differs from the administrative allocation and market-based mechanisms significantly as it does not define individual spectrum access rights but allows market entry to different wireless systems potentially deployed by a variety of stakeholders based on shared access to the spectrum. The unlicensed commons approach has been the source of success for wireless local area networks (WLAN) that can be deployed by any stakeholder not having to be an MNO. The unlicensed commons approach has not traditionally attracted cellular mobile communication networks whose deployment was based on individual access rights but in the $4 \mathrm{G}$ and $5 \mathrm{G}$ era, the cellular community has wanted to introduce $4 \mathrm{G}$ and $5 \mathrm{G}$ variants for unlicensed access to share the spectrum bands with the dominant WiFi technology and other users of the unlicensed spectrum [5].

\section{B. Recent $5 G$ Spectrum Decisions}

At the global level, the spectrum decisions made at the WRCs of the ITU-R have allocated new spectrum bands for the mobile service with identification for IMT systems in multiple occasions. 5G has not been an exception and most recently in 2019 new spectrum was identified for IMT [2]. The process of new spectrum allocations at the global level is a very time-consuming where the time spans typically are in the order of 10 years from the start of the process until the band is available [15]. In the rapid technology development, these time-scales set limits on the deployment of cellular networks.

In the national level, national regulators have recently made $5 \mathrm{G}$ spectrum awards decisions to allow the commercial deployment of $5 \mathrm{G}$ networks. According to a recent overview on $5 \mathrm{G}$ spectrum awards decisions [3], there is divergence in the approaches that the national regulators have taken. Market-based mechanisms through spectrum auctions dominate the awards, but some auctions are designed to support administrative allocation paradigm without introducing real market mechanism. A major change observed in $5 \mathrm{G}$ decisions was in how the administrations see the uptake of local $5 \mathrm{G}$ networks that particularly address location specific needs of vertical sectors [4]. Regulators in several countries have recently allowed local $5 \mathrm{G}$ spectrum access rights to non-traditional mobile network operators or are in the process of doing so [3].

Another specificity in spectrum management decisions for $5 \mathrm{G}$ compared to prior generations is the wide variety of spectrum bands whose characteristics differ in an unforeseen way. In Europe, the major spectrum bands considered for $5 \mathrm{G}$ include $700 \mathrm{MHz}, 3.5 \mathrm{GHz}$ and $26 \mathrm{GHz}$ [16] which have very different propagation characteristics resulting in very different network coverage areas ranging from tens of meters to tens of kilometers. Deployment models range from widearea coverage to indoor deployments which call for different expertise and assets. Thus, it has become clear that a wide variety of spectrum management approaches are needed in the $5 \mathrm{G}$ era compared to prior generations.

Cellular mobile communication networks are also entering the unlicensed spectrum. The advantage of unlicensed commons approach is fast time to spectrum and network deployment based on business with no the need to apply for licenses or to pay the accompanying license fees. Lowered barrier to entry could be beneficial particularly in novel local private enterprise use cases. On the other hand, unlicensed commons spectrum cannot meet the requirements for large scale network deployments due to the high risk of mutual harmful interference and the technical restrictions applied to unlicensed use, like required co-existence mitigation techniques and low maximum transmit power limit.

Utilization of the unlicensed commons approach for $5 \mathrm{G}$ cellular mobile communication networks will further increase the variety of spectrum bands. $5 \mathrm{G}$ new radio in unlicensed band (NR-U) is planned to start with 3GPP release 16 in 2020 at $5 \mathrm{GHz}$ where the bands $5150-5350$ $\mathrm{MHz}$ and $5470-5725 \mathrm{MHz}$ are available for radio local area networks (RLANs) [17]. The FCC in the US and several other countries have defined also the band $5725-5850 \mathrm{MHz}$ where many current private LTE networks operate using a higher output power and not requiring co-existence mitigation technique like listen before talk (LBT) [18].

Discussions on the future of the $6 \mathrm{GHz}$ band are taking place around the world. Some countries have proposed license-exempt in the band (United States), others have decided to move towards licensed IMT use (China), while others may decide to split the band for license-exempt and licensed operation. Both in the US and in Europe, there are studies ongoing on the possibilities to make $6 \mathrm{GHz}$ spectrum available for RLAN-type and other license exempt use to complement $5 \mathrm{GHz}$ wireless access systems. FCC is 
considering 5925-6425 MHz and 6425-7125 MHz for unlicensed use [19]. As the band is heavily used by fixed links requiring protection, an Automated Frequency Coordination (AFC) System is being proposed. Similarly, in Europe, EC issued a mandate to study the band 5925-6425 $\mathrm{MHz}$ for unlicensed use and studies are on-going. On the other hand, The People's Republic of China and five other countries in the Asia Pacific region have promoted the IMT identification for the $5925-7425 \mathrm{MHz}$ for licensed use. Moreover, in the $60 \mathrm{GHz}$ band studies are on-going and spectrum regulation exists for the US [20] and Europe [21]. To complement cellular offering, many MNOs are in progress of adding IEEE P802.11ax [22] standard based WiFi 6 to their in-home connectivity portfolios to address quality of experience issues and to improve multi-device entertainment and connected home propositions. Wi-Fi 6 will support the roll-out of multi-gigabit fiber and cable services in many countries, providing faster and more-reliable services for individual premises, rooms and applications.

The recent $5 \mathrm{G}$ spectrum related developments and decisions indicate that a wide variety of spectrum management approaches are now included into mobile communication networks in great contrast to the prior generations of cellular networks. The trend that now has started is expected to continue towards the $6 \mathrm{G}$ era. Table I gives examples of recent $5 \mathrm{G}$ spectrum awards showcasing the different spectrum management approaches taken or planned in different countries/areas with an emphasis on how they consider local network deployments.

TABLE I. 5G SPECTRUM AWARDS IN DIFFERENT COUNTRIES.

\begin{tabular}{|c|c|}
\hline Country/Area & Highlights of 5G spectrum awards \\
\hline Finland & $\begin{array}{l}\text { Low price paid and wide per operator bandwidths made } \\
\text { available at } 3.5 \mathrm{GHz} \text { band. } 26 \mathrm{GHz} \text { planned to be } \\
\text { auctioned nation-widely and part to be set aside for local } \\
\text { networks. }\end{array}$ \\
\hline Germany & $\begin{array}{l}\text { High revenues collected in spectrum auction of } 3.5 \mathrm{GHz} \\
\text { band and coverage obligations introduced. Local licensing } \\
\text { introduced in part of the band. }\end{array}$ \\
\hline Italy & $\begin{array}{l}\text { Spectrum pool at } 26 \mathrm{GHz} \text { for spectrum sharing between } \\
\text { users. }\end{array}$ \\
\hline UK & Local licensing introduced in several bands. \\
\hline USA & $\begin{array}{l}3 \text { tier CBRS service with spectrum access system to } \\
\text { manage the sharing arrangements between different levels } \\
\text { of spectrum access rights including regional licenses and } \\
\text { unlicensed local access. }\end{array}$ \\
\hline Australia & $\begin{array}{l}24 \mathrm{GHz} \text { sub-bands for wireless broadband limited to } \\
\text { private property (including domestic, industrial, business, } \\
\text { commercial and government use cases). }\end{array}$ \\
\hline Japan & $\begin{array}{l}28 \mathrm{GHz} \text { "local 5G" bands made available for specific } \\
\text { vertical applications. The licenses will be granted to the } \\
\text { owners of the land or property. }\end{array}$ \\
\hline France & $\begin{array}{l}\text { Enterprises can apply to } 2.6 \mathrm{GHz} \text { TDD spectrum (2575- } \\
2615 \mathrm{MHz} \text { ) for local deployments. }\end{array}$ \\
\hline Hong Kong & $\begin{array}{l}\text { At } 28 \mathrm{GHz} \text { band } 400 \mathrm{MHz} \text { reserved for Localized } \\
\text { Wireless Broadband Service (LWBS) based on licensed } \\
\text { geographical sharing, 1st-come-1 st-served. }\end{array}$ \\
\hline
\end{tabular}
for shared spectrum access and calculated the conditions for sharing [26]. In fact, some administrations are currently in the process of making the $2.3 \mathrm{GHz}$ band available for $4 \mathrm{G} / 5 \mathrm{G}$ through shared spectrum access using the databases which make use of the recently approved ETSI evolved LSA (eLSA) approach.

Additionally, the three-tier spectrum sharing model in 3.55-3.70 GHz band in the US for citizens broadband radio service (CBRS) is based on the database approach (namely the spectrum access system, SAS) and additionally uses sensing for the protection of a specific incumbent wireless service [27]. The final FCC rules [28] provide two paths for the spectrum, priority access license (PAL) and general authorized access (GAA). The PAL spectrum is planned to be auctioned off in the mid 2020 in smaller regional areas, in 3200 counties, for ten years licenses with possibility of renewal. In comparison, to date many spectrum auctions in the US are done over 416 Partial Economic Areas that has made it expensive and not viable for an enterprise to acquire. The cost to acquire a single $10 \mathrm{MHz}$ PAL will be determined by a spectrum auction but should be reasonably priced compared to other cellular spectrum auctions. The rules allow for a single PAL licensee to hold up to four channels in any licensed area at any given time, providing up to $40 \mathrm{MHz}$ of spectrum protected from interference. Furthermore, the PAL holders are allowed to lease their partitioned and or disaggregated PAL spectrum beyond their deployment coverage but within their PAL area. A second path for spectrum in the CBRS band is to use $80 \mathrm{GHz}$ of opportunistic, licensed by the rule GAA spectrum. Additionally, spectrum not currently used by an incumbent 
or by a PAL holder is available for GAA users on a shared basis. Initial commercial deployment has started, and SASs have been approved.

After a long development phase, the use of databases has started to enable spectrum sharing. However, its wide-spread applications to cellular mobile communication networks are still very limited but the deployment of databases will continue and become increasingly important in the future.

\section{B. Emerging Enabling Technologies}

Interference management is at the heart of spectrum sharing and techniques to optimize and manage a large number of wireless devices with time and location varying transmission patterns could facilitate spectrum sharing but have turned out to be computationally very complex. Artificial intelligence (AI) inspired algorithms for spectrum sharing have attracted increasing attention recently with the advances in computing resources.

Databases continue to be important enabler for spectrum sharing by offering the platform where data of spectrum use is stored and managed, see e.g. [29]. Various technologies can be deployed on top of databases such as blockchains that are studied for spectrum management [30]. The shift towards the use of unlicensed bands for cellular networks calls for the development of new coordination techniques to improve spectrum usage efficiency of future networks [31]

Finally, the methods for obtaining accurate awareness of spectrum usage and resulting spectrum availability continue to evolve from traditional spectrum sensing towards accurate situational awareness. The merging of locationing, sensing and communication in future networks [6] can be used to obtain more accurate status of the radio environment, expanding radio environment maps to more dynamic operations.

\section{SPECTRUM DisCUSSIONS FOR 6G FUTURE NETWORKS}

Spectrum discussions for $6 \mathrm{G}$ networks are currently at their infancy. With the advent of a new generation of mobile communication networks, the quest for new spectrum bands leads to a global process in the ITU-R level through WRCs, see e.g., [15]. In the past decades, getting new spectrum bands for mobile communication networks has resulted in rivalry with the existing holders of spectrum access rights to the new bands envisages for mobile communications. Thus, any new global developments for $6 \mathrm{G}$ spectrum face the same old challenges of the process being very slow and prone to conflict. The agenda for the next WRC in 2023 will contain very limited study items for new spectrum for IMT systems indicating that $6 \mathrm{G}$ spectrum studies at the ITU level will not yet take place yet. At the same time, national developments are surpassing the role of international level harmonization if the national market for new wireless equipment is big enough. This can lead to fragmentation but at the same time allows faster time cycles to deploy new technologies.

$6 \mathrm{G}$ research has identified terahertz spectrum as a major domain for mobile communication networks [6]. Additionally, the spectrum bands currently used for $2 \mathrm{G} / 3 \mathrm{G} / 4 \mathrm{G} / 5 \mathrm{G}$ in many countries continue to be available for future $6 \mathrm{G}$ networks. The resulting range of spectrum bands for $6 \mathrm{G}$ will thus be greater than ever leading to a variety of spectrum management approaches needed to address the differences of the mid, high and even higher bands. 6G will need to be flexible to operate in multiple bands and under different spectrum management approaches. The role of local networks [3] continues to become important in 6G [6] and needs to be supported by spectrum management models.

The quest of new spectrum for $6 \mathrm{G}$ faces the same barrier as before - how to deal with the existing spectrum users. The need for spectrum sharing in $6 \mathrm{G}$ to protect the incumbents spectrum users is higher than ever before, which can open new bands for the networks. 6G will merge sensing with communications when going to the higher frequencies [6]. This development together with advances in the spectrum access decision making through AI inspired algorithms opens the door for more dynamic operations where the $6 \mathrm{G}$ networks can sense the radio environment and adapt in real time. Mobile communication networks are increasingly planned to be used for serving the communication needs of utilities and industries which previously have had dedicated spectrum and solutions. In addition, new types of flexible AIenabled users and use cases that cross the boundaries of dedicated spectrum and solutions may emerge. Thus, the traditional spectrum division to different services is blurred with the mobile communication networks being used for different purposes. Moreover, the role of politics has already taken a big place in 5G discussions with various governments taking positions in the importance of highcapacity networks is the digitalization of various vertical sectors. In 6G, digital inclusion becomes a key discussion topic, which directly depends on the availability of spectrum. The current MNO driven market will face a move to communities centered approach.

\section{IDENTIFIED CHALLENGES AND FUTURE OUTLOOK}

Many challenges and open research questions for spectrum management in the future $6 \mathrm{G}$ era exist, see Table II. The same major challenges still exists for regulators, including how to maximize the efficiency of spectrum use and the value of spectrum and how to strike a balance between conflicting claims of different stakeholders wishing to deploy their own wireless systems. This development will inevitably call for spectrum sharing more than what has been witnessed by now. This breaks down into more detailed challenges for spectrum management in the $6 \mathrm{G}$ era which are discussed next.

Divergence of spectrum management approaches has started in $5 \mathrm{G}$ and will continue in $6 \mathrm{G}$. The bands vary from low, mid, high and $\mathrm{THz}$ spectrum ranges which call for different approaches and the evidence is still limited. The use of market mechanisms is still limited and transactions in practice occur seldom if operators possessing the spectrum access rights do not wish to sell them in the fear of increasing competition. Therefore, more research is needed on how to take market mechanisms into use in the $5 \mathrm{G}$ and 6G era. Especially new spectrum awarding mechanisms including valuation and pricing mechanisms need to be developed that spur innovation while attracting investments.

The long time spans involved in making new spectrum available and the difficulties of sharing the spectrum between different radio services continue to be a true challenge. Interference management between the different radio systems calls new ways to define feasible protection requirements that are realistic and not overly protective and technical solutions that allow deployment. 
TABLE II. Challenges In the 6G SPECtrum Management ERA.

\begin{tabular}{|c|c|}
\hline $\begin{array}{l}\text { Challenge } \\
\text { (type) }\end{array}$ & Related research questions \\
\hline $\begin{array}{l}\text { Divergence of spectrum } \\
\text { management approaches } \\
\text { (regulation) }\end{array}$ & $\begin{array}{l}\text { What are the most suitable spectrum } \\
\text { management approaches in different frequency } \\
\text { bands (low, mid-, high, THz spectrum ranges)? }\end{array}$ \\
\hline $\begin{array}{l}\text { Spectrum } \\
\text { (regulation } \\
\text { technology) }\end{array}$ & $\begin{array}{l}\text { How to create well-functioning low transaction } \\
\text { cost spectrum marketplace for different needs } \\
\text { (e.g. local networks)? }\end{array}$ \\
\hline $\begin{array}{l}\text { Spectrum valuation and } \\
\text { pricing (regulation) }\end{array}$ & $\begin{array}{l}\text { How to price spectrum for localized } \\
\text { deployments for various vertical use cases? }\end{array}$ \\
\hline \begin{tabular}{lr} 
Long time & \multicolumn{1}{c}{ spans for } \\
international & spectrum \\
decision & making \\
(regulation) &
\end{tabular} & $\begin{array}{l}\text { How could spectrum sharing facilitate the } \\
\text { introduction of new entrants to spectrum } \\
\text { bands? How to protect incumbent spectrum } \\
\text { users from harmful interference }\end{array}$ \\
\hline $\begin{array}{l}\text { Interference } \\
\text { management } \\
\text { (technology) }\end{array}$ & $\begin{array}{l}\text { How to coordinate interference between } \\
\text { different wireless systems with different levels } \\
\text { of access rights? }\end{array}$ \\
\hline $\begin{array}{l}\text { Interf } \\
\text { mana }\end{array}$ & $\begin{array}{l}\text { o define feasible protection requirements } \\
\text { en incumbent and entrant systems? }\end{array}$ \\
\hline
\end{tabular}

\section{CONCLUSIONS}

Spectrum management in the $6 \mathrm{G}$ era will reveal a new level of complexity that stems from the variety of spectrum bands and spectrum management models with different levels of spectrum sharing. Traditional MNO driven deployment of mobile communication networks is already starting to be complemented by local deployments of $5 \mathrm{G}$ networks by a variety of stakeholders made possible by regulators in many countries. At the same time, cellular deployments in unlicensed bands start change the traditional long-term wide-area network deployment paradigm. These trends are expected to further grow in 6G. Spectrum sharing will play increasing role in accommodating new $6 \mathrm{G}$ systems with incumbents. The time-scales of international-level spectrum management are no longer sufficient with the rapid technology development of mobile communication networks and changing user needs when the networks begin to be used for different purposes.

\section{ACKNOWLEDGMENT}

The authors would like to acknowledge 5G-VIIMA project funded by Business Finland and Academy of Finland in 6G Flagship program (grant no. 318927).

\section{REFERENCES}

[1] P. Anker, "From spectrum management to spectrum governance," Telecommunications Policy, vol. 41, no. 5-6, pp. 486-497, 2017.

[2] ITU, World Radiocommunication Conference 2019 (WRC-19) Provisional Final Acts. 2019. 568 p.

[3] M. Matinmikko-Blue, S. Yrjölä, V. Seppänen, P. Ahokangas, H Hämmäinen, and M. Latva-aho. Analysis of Spectrum Valuation Elements for Local 5G Networks: Case Study of 3.5 GHz Band. IEEE Trans. Cogn. Commun. Networking, vol. 5, no. 3, pp. 741-753, 2019.

[4] M. Matinmikko, M. Latva-aho, P. Ahokangas, and V. Seppänen. On regulations for 5G: Micro licensing for locally operated networks. Telecommunications Policy, Vol. 42, No. 8, Sept. 2018, pp. 622-635.

[5] P. Ojanen, S. Yrjölä, and M. Matinmikko-Blue. Assessing the Feasibility of the Spectrum Sharing Concepts for Private Industrial
Networks Operating above 5 GHz. EuCAP 2020, 15-20 March 2020, Copenhagen, Denmark.

[6] M. Latva-aho \& K. Leppänen (eds.) Key Drivers and Research Challenges for 6G Ubiquitous Wireless Intelligence. 6G White Paper, September 2019.

[7] H. J. Levin, "Spectrum allocation without market," The American Economic Review, vol. 60, no. 2, pp. 209-218, 1970.

[8] W. H. Melody, "Radio spectrum allocation: Role of the market," The American Economic Review, vol. 70, no. 2, pp. 393-397, 1980.

[9] F. Beltran, "Accelerating the introduction of spectrum sharing using market-based mechanisms," IEEE Communications Standards Magazine, vol. 1, no. 3, pp. 66-72, 2017.

[10] K. R. Carter, "Policy lessons from personal communications services: Licensed vs. unlicensed spectrum access," CommLaw Conspectus J. Commun. Law Policy, vol. 15, no. 1, pp. 93-117, 2006.

[11] T. Kuroda and M. D. P. B. Forero, "The effects of spectrum allocation mechanisms on market outcomes: Auctions vs beauty contests," Telecommunications Policy, vol. 41, no. 5-6, pp. 341-354, 2017.

[12] P. Cramton, "Spectrum auction design," Review of Industrial Organization, vol. 42, no. 2, pp. 161-190, 2013.

[13] T. M. Valletti, "Spectrum trading," Telecommunications Policy, vol. 25, no. 10-11, pp. 655-670, 2001.

[14] C. Bazelon, "Licensed or unlicensed: The economic considerations in incremental spectrum allocations," IEEE Communications Magazine, vol. 47, no. 3, 2009, pp. 110-116.

[15] Takagi, H. and Walke, B.H. eds., 2008. Spectrum requirement planning in wireless communications: Model and metholody or IMTAdvanced (Vol. 2). John Wiley \& Sons.

[16] European Commission, "Strategic spectrum roadmap towards 5G for Europe: RSPG second opinion on $5 \mathrm{G}$ networks," Radio Specrum Policy Group (RSPG), RSPG18-005, 2018.

[17] EU/CEPT requirements (compliant with ITU-R requirements): ECC Decision (04)08

[18] FCC U-NII requirements: CFR Part 15, Sub-part E

[19] FCC ruling proposal: NPRM Doc FCC 18-147.

[20] FCC: Part 15, $\$ 15.255$, operation in $57-71 \mathrm{GHz}$ :

[21] ERC Rec 70-03 Annex 3: $57-71 \mathrm{GHz}$ for Wideband Data Transmission Systems

[22] IEEE Draft Standard for Information Technology, P802.11ax

[23] ECC, Technical and operational requirements for the possible operation of cognitive radio systems in the "white spaces" of the frequency band 470-790 MHz. ECC Report 159. 2011.

[24] ECC, "Report 205 Licensed Shared Access (LSA)," 2014.

[25] M. Palola et al., "Live field trial of Licensed Shared Access (LSA) concept using LTE network in $2.3 \mathrm{GHz}$ band," 2014 IEEE International Symposium on Dynamic Spectrum Access Networks (DYSPAN), McLean, VA, 2014, pp. 38-47.

[26] D. Guiducci et al., "Regulatory Pilot on Licensed Shared Access in a Live LTE-TDD Network in IMT Band 40," in IEEE Transactions on Cognitive Communications and Networking, vol. 3, no. 3, pp. 534549, Sept. 2017.

[27] FCC: Part 96 - Citizens Broadband Radio Service. (2015).

[28] FCC: Increasing Incentives for Investment and Innovation in $3.5 \mathrm{GHz}$ Band. https://www.fcc.gov/document/increasing-incentivesinvestment-and-innovation-35-ghz-band, last accessed 2019/01/02.

[29] M. Höyhtyä, A. Mämmelä, A. Chiumento, S. Pollin, M. Forsell and D. Cabric, "Database-Assisted Spectrum Prediction in 5G Networks and Beyond: A Review and Future Challenges," in IEEE Circuits and Systems Magazine, vol. 19, no. 3, pp. 34-45, 2019.

[30] M. B. H. Weiss, K. Werbach, D. C. Sicker and C. E. C. Bastidas, "On the Application of Blockchains to Spectrum Management," in IEEE Transactions on Cognitive Communications and Networking, vol. 5, no. 2, pp. 193-205, June 2019.

[31] J. Jeon, R. D. Ford, V. V. Ratnam, J. Cho and J. Zhang, "Coordinated Dynamic Spectrum Sharing for 5G and Beyond Cellular Networks," in IEEE Access, vol. 7, pp. 111592-111604, 2019. 